\title{
O DIREITO AO ESQUECIMENTO NA INTERNET É UM DIREITO FUNDAMENTAL?
}

\section{${ }^{1}$ Vinícius Borges Fortes ${ }^{2}$ José Renato Gaziero Cella}

\section{RESUMO}

Baseado no conceito de direitos de privacidade na internet, esta pesquisa tem como objetivo geral analisar a aplicação de um direito ao esquecimento como extensão do direito fundamental à privacidade e à proteção de dados pessoais. O trabalho identifica que o conceito de direito ao esquecimento relaciona-se, na contemporaneidade, com o right to be forgotten, tendo relação direta com o direito à proteção de dados pessoais na internet. $\mathrm{O}$ estudo conclui que conceber a privacidade na internet como um direito fundamental significa dizer que o direito ao esquecimento pode ser um dos pilares de eficácia do direito fundamental à privacidade.

Palavras-chave: Direitos de privacidade na internet, Direitos fundamentais, Internet, Privacidade, Dados pessoais, Direito ao esquecimento

\section{¿EL DERECHO AL OLVIDO EN INTERNET ES UN DERECHO FUNDAMENTAL?}

\section{RESUMEN}

Basado con el concepto de derechos de privacidad en Internet, la aplicación de "un" derecho al olvido como una extensión del derecho fundamental a la privacidad y protección de datos personales. Luego, el trabajo identifica el concepto de derecho al olvido, en la época contemporánea, con el "right to be forgotten", que tiene relación directa con el derecho a la protección de datos personales en Internet. El estudio concluye que concebirás de la privacidad en Internet como un derecho fundamental significa que el derecho al olivido puede ser una garantía efectiva de los pilares del derecho fundamental a la privacidad.

Palabras-claves: Derechos de privacidad en internet, Derechos fundamentales, Internet, Privacidad, Datos personales, Derecho al olvido

\footnotetext{
${ }^{1}$ Doutor em Direito pela Universidade Estácio de Sá - UNESA Rio de Janeiro, Brasil. Pesquisador da Universidade de Zaragoza - UNIZAR, Espanha. E-mail: vinibfortes@gmail.com (Brasil)

2 Doutor em Filosofia e Teoria do Direito pela Universidade Federal de Santa Catarina - UFSC, Brasil. Pesquisador da Universdad de Zaragoza - UNIZAR, Espanha. E-mail: cella@cella.com.br
} 


\section{INTRODUÇÃO}

A evolução da história da humanidade se reflete, também, na capacidade de comunicação e transmissão de informações. Com a internet, o direito à informação expandiuse, facilitando o acesso ao conhecimento, nos mais diversos pontos do planeta. $\mathrm{O}$ ciberespaço se constituiu enquanto rede aberta com a possibilidade de interagir, gerar dados, navegar e estabelecer relações na rede.

Esta pesquisa adota o entendimento da palavra 'privacidade' como conceito amplo para determinar a proteção do direito fundamental à proteção da vida privada e da intimidade, bem como a inviolabilidade dos dados pessoais, a partir da incorporação conceitual dos direitos de privacidade na internet (FORTES, 2015).

O estudo busca responder à seguinte indagação: à luz dos direitos fundamentais no contexto da internet no Brasil, o direito ao esquecimento pode ser considerado um direito fundamental decorrente da proteção e inviolabilidade do direito à privacidade e à proteção de dados pessoais?

A investigação tem como objetivo geral analisar a aplicação de "um" direito ao esquecimento no contexto dos direitos fundamentais na internet, buscando cumprir com os seguintes objetivos específicos: (i) apresentar os fundamentos conceituais dos direitos fundamentais, em especial aos novos direitos advindos do uso da Internet; das origens históricas e conceituais da privacidade; e dos fundamentos jurídico-normativos da proteção dos dados pessoais em sentido amplo; (ii) analisar, a partir dos fundamentos dos direitos fundamentais, o reconhecimento de novos direitos relacionados à proteção da privacidade $\mathrm{e}$ dos dados pessoais na Internet, em especial os quatro direitos-base que compõem a estrutura conceitual de direitos de privacidade na internet, aprofundando a análise do terceiro direitobase, qual seja o de deletar dados pessoais e a sua relação com o direito ao esquecimento.

Para desenvolver a investigação proposta nesta tese, dentre os métodos de pesquisa, serão utilizados os métodos de procedimento comparativo e histórico, de modo a estabelecer relações e análises dentro da historicidade vinculada aos aspectos da internet e do Direito, da evolução dos direitos fundamentais até o efetivo reconhecimento da privacidade enquanto direito. O tipo de pesquisa desenvolvido tem natureza qualitativo-exploratória, e a técnica ficará limitada à análise bibliográfica em fontes primárias e secundárias. 


\section{O DIREITO À PRIVACIDADE E À PROTEÇÃO DOS DADOS PESSOAIS COMO DIREITOS FUNDAMENTAIS}

De modo emblemático, o artigo intitulado "The Right to Privacy", de autoria de Warren e Brandeis, na Harvard Law Review, no ano de 1890, representou um marco para o debate jurídico sobre o tema da privacidade (WARREN; BRANDEIS, 1890). No texto, os autores analisam o contexto das invenções recentes da época e os novos métodos de negócio para chamar a atenção, surgindo a necessidade de instrumentos jurídicos de proteção da pessoa, de modo a assegurar o que Cooley denominou, anos antes, 'o direito de ser deixado em paz', ou originalmente 'the right to be let alone' (WARREN; BRANDEIS, 1890).

No contexto do artigo que se tornou um paradigma para o estudo jurídico da privacidade, as fotografias instantâneas publicadas pelas empresas jornalísticas invadiram a vida privada e familiar. Por isso, durante certo tempo houve a sensação de que o direito deveria oferecer alguma solução para a circulação não autorizada de fotografias privadas de pessoas. A intensidade e a complexidade da vida, que acompanham os avanços da civilização, provocaram a necessidade de certo distanciamento do mundo. Os indivíduos, influenciados pela cultura da época, viram-se mais vulneráveis à publicidade, de modo que a solidão e a intimidade se transformaram em algo essencial às pessoas. Para os referidos autores, os novos modos de difusão da informação e as novas tecnologias vinculadas a esses modos, ao invadirem a intimidade de outrem, produzem um sofrimento espiritual e uma angústia que superam meros danos pessoais (WARREN; BRANDEIS, 1890).

De acordo com Saldaña (2012), que analisou historicamente os fundamentos e o contexto que levaram à publicação do artigo de Warren e Brandeis (1890), as possibilidades invasivas da tecnologia fizeram com que os autores manifestassem a necessidade de definir um princípio que pudesse ser invocado para amparar a intimidade do indivíduo frente à imprensa, ao fotógrafo ou a qualquer outro possuidor de um aparato de reprodução de imagens ou sons.

Assim, materializou-se o conceito por eles defendido de um direito à privacidade, originalmente denominado 'the right to privacy', o qual outorga a toda a pessoa plena disponibilidade para decidir em que medida podem ser comunicados a outros seus pensamentos, sentimentos e emoções. O que significa dizer, nesse contexto, que a finalidade do direito passa a ser a de garantir àquelas pessoas cujos assuntos não são causa de preocupação legítima para a parcela da sociedade que não se vê conduzida por uma publicidade indesejável e indesejada, bem como proteger essas pessoas, seja quem elas forem, 
independente de status ou posição social, de verem divulgados, contra sua vontade, assuntos prefeririam manter absolutamente reservados (WARREN; BRANDEIS, 1890).

O direito à privacidade, contudo, garante a proteção aos âmbitos mais imateriais, aos interesses espirituais da pessoa, configurando-se como um direito autônomo que adquire substantividade própria. Por essa razão, Warren e Brandeis fundamentaram diretamente o denominado 'right to privacy' no direito de desfrutar a vida, rechaçando expressamente qualquer conexão ou associação com os direitos de liberdade ou propriedade. Eles situaram o direito à privacidade em uma categoria geral do direito individual de ser deixado em paz ou de, simplesmente, não ser incomodado (right to be let alone) (SALDAÑA, 2012).

Outra questão relevante concentra-se na distinção proposta entre o âmbito privado, reservado ao indivíduo, e o âmbito público ou geral, de legítimo conhecimento pelo conjunto da sociedade. Esta diferenciação vai ao encontro da tradição do direito anglo-americano e da cultura jurídica europeia, que se basearam na clássica distinção entre jus publicum e jus privatum (SALDAÑA, 2012).

No caso em que originou a reflexão sobre o direito à privacidade, a common law assegurava a cada pessoa o direito de dizer até que ponto podem ser comunicados a outrem seus pensamentos, sentimentos e emoções. Dentro desse sistema, nunca se pode forçar alguém a expressá-los (exceto na condição de testemunha) e, ainda que decida expressá-los, o sujeito tem, por regra geral, o poder de fixar os limites da publicidade. Assim, a existência desse direito não depende do meio de difusão da informação utilizado. Não importa se for por meio de palavras ou códigos, por pintura, escultura ou música. A existência desse direito não depende tampouco da natureza do valor do pensamento, nem da qualidade dos meios empregados para sua expressão. Em qualquer desses casos, o autor é quem tem o direito de decidir se o que é seu deve sair à 'luz pública' (WARREN; BRANDEIS, 1890).

Em continuidade à percepção conceitual do direito à privacidade concebido por Warren e Brandeis (1890), Tapper (1973) diz que, em um mundo no qual a reprodução das espécies não é realizada espontaneamente e a sobrevivência depende da cooperação dos outros, não é possível ocorrer a exclusão de um indivíduo da vida do outro. Nesse contexto, os outros têm olhos, ouvidos e língua, são curiosos e adoram fofocar. Verifica-se, pois, que a privacidade existe naturalmente nas mais primitivas comunidades, ainda que, por vezes, expressa na forma de rituais. No contexto vivenciado na década de 1970, a privacidade possuía facetas do desejo por isolamento, anonimato e pelo direito de controle da disseminação de informações sobre si mesmo, representando uma criação advinda essencialmente da civilização urbana. 
De modo diverso à concepção de que a privacidade representa apenas o direito de ser deixado em paz ou de não ser incomodado, Warner e Stone (1970) defendem ser essa uma concepção paradoxal, pois privacidade também significa o direito de se comunicar, assegurando-se, contudo, de que as informações geradas não serão utilizadas contra o indivíduo que as produziu.

Assim, a privacidade passou a ser considerada uma 'virtude extremamente escorregadia', intangível, sobre a qual é difícil estabelecer uma definição e eventuais mensurações. Significa dizer que um 'direito à privacidade' não é e não pode ser um estatuto imutável. Para diferentes pessoas possui sentidos diferentes em espaços de tempo diversos e está diretamente ligado com o que se compreende por anonimato (WARNER; STONE, 1970).

Em contraponto à construção proposta por Warren e Brandeis (1890) sobre a efetivação do direito à privacidade, Warner e Stone (1970) defendem que, à época da publicação ora referenciada, o direito não conferia um 'direito de privacidade', nem no Reino Unido, nem na maior parte dos Estados norte-americanos. Isso porque está esse direito assegurado apenas em relação à proteção legal de reputações e propriedades, não garantindo proteção à dor emocional trazida com a invasão da privacidade de outrem.

Ainda assim, é possível afirmar que a privacidade encontra reconhecimento como direito humano e, portanto, como direito fundamental, sobretudo ao manto dos fundamentos apresentados por Warren e Brandeis (1890) e Warner e Stone (1970).

$\mathrm{O}$ primeiro documento internacional a recepcionar o direito à privacidade foi a Declaração Americana dos Direitos do Homem ${ }^{1}$, explicitando, no artigo V, que "Toda pessoa tem direito à proteção da lei contra os ataques abusivos à sua honra, à sua reputação e à sua vida particular e familiar”. Na sequência, a Declaração Universal dos Direitos Humanos, legitimada por seus signatários, no ano de 1948, expressa, no artigo 12, que "Ninguém será sujeito à interferência em sua vida privada, em sua família, em seu lar ou em sua correspondência, nem a ataque à sua honra e reputação. Todo ser humano tem direito à proteção da lei contra tais interferências ou ataques" (ASSEMBLEIA GERAL DAS NAÇÕES UNIDAS, 1948).

Ainda no sentido de reconhecer o direito à proteção da vida privada como um direito humano, a Convenção Europeia para a Proteção dos Direitos do Homem e das Liberdades

\footnotetext{
1 “"...] Note-se que a privacidade, após a Segunda Guerra, passou a encontrar abrigo certo em varias declarações internacionais de direitos. Sua primeira menção foi em 1948, na Declaração Americana dos Direitos do Homem, vindo a seguir, no mesmo ano, sua presença na Declaração Universal dos Direitos do Homem, aprovada pela Assembleia Geral das Nações Unidas; [...]” (DONEDA, 2006, p. 09)
} 
Fundamentais, aprovada em Roma, no ano de 1950, apresentou, em seu artigo $8^{\circ}$, o "Direito ao respeito pela vida privada e familiar".

Em um sentido desapegado de regimes de exceção, o artigo 17 do Pacto Internacional sobre Direitos Civis e Políticos, aprovado, no ano de 1966, pela Assembleia Geral das Nações Unidas e recepcionado, em 1992, pelo Brasil, que o convalidou por meio do Decreto n. ${ }^{\circ} 592$ (BRASIL, 1966), legitima a proteção da vida privada.

Nesse aspecto, convém destacar a lição de Rodotà (2008, p. 17):

[...] A distinção entre o direito ao respeito da vida privada e familiar e o direito à proteção dos dados pessoais não é bizantina. $\mathrm{O}$ direito ao respeito da vida privada $\mathrm{e}$ familiar reflete, primeira e principalmente, um componente individualista: este poder basicamente consiste em impedir a interferência na vida privada e familiar de uma pessoa. Em outras palavras, é um tipo de proteção estático, negativo. Contrariamente, a proteção de dados estabelece regras sobre os mecanismos de processamento de dados e estabelece a legitimidade para a tomada de medidas - i.e. é um tipo de proteção dinâmico, que segue o dado em todos os seus movimentos. [...] É de fato o fim da linha de um longo processo evolutivo experimentado pelo conceito de privacidade - de uma definição original como o direito de ser deixado em paz, até o direito de controle sobre as informações de alguém e determinar como a esfera privada deve ser construída.

Ao tratar dos fundamentos históricos da proteção jurídica dos dados pessoais, é relevante observar sua gênese. Contudo, convém ressaltar o entendimento de Rodotà (2008) de que, hodiernamente, vivencia-se uma reinvenção conceitual da proteção de dados, não apenas pelo reconhecimento expresso como direito fundamental autônomo, mas pelo papel indispensável para o desenvolvimento da personalidade. Assim, “[...] A proteção de dados pode ser vista como a soma de um conjunto de direitos que configuram a cidadania do novo milênio" (RODOTÀ, 2008, p. 17).

É com base nesses fundamentos que Rodotà (2008) afirma que a proteção de dados não é apenas um direito fundamental, mas o mais significativo da humanidade na contemporaneidade. Em sentido análogo, Doneda (2006) refere que o tema da privacidade adota, cada vez mais, uma estrutura em torno da informação e, de modo específico, dos dados pessoais, o que pode ser observado na evolução normativa relacionada ao tema. Em que pese existirem diferenças conceituais, a proteção jurídica do direito à privacidade conecta-se com o direito à inviolabilidade dos dados pessoais, previsto em diversos diplomas legais, inclusive com o reconhecimento, como direito fundamental, conforme aprofundado ao longo da pesquisa.

Evidentemente, o aumento considerável da presença de computadores e do acesso à internet nos domicílios possibilita o potencial aumento do número de indivíduos sujeitos a 
transgressões de direitos na internet, especialmente do direito fundamental à privacidade através da violação dos dados pessoais. Além dos riscos relacionados à mineração de dados por empresas privadas, especializadas na coleta de dados privados para fins comerciais, os usuários de serviços de internet e telefonia móvel estiveram (e possivelmente estejam e ainda estarão no futuro) sujeitos a práticas de vigilância em massa pelo governo dos EUA, pelos programas da NSA (GREENWALD; KAZ; CASADO, 2013).

A partir da Resolução n. ${ }^{\circ}$ 69/166, de 18 de dezembro de 2014, emitida pela Assembleia Geral das Nações Unidas, em especial após propostas apresentadas pelo Brasil em conjunto com a Alemanha, foi aprovada, no mês de março do ano 2015, a constituição de uma relatoria especial do Conselho de Direitos Humanos para acompanhamento das questões relacionadas às violações ao direito humano à privacidade em âmbito global (ASSEMBLEIA GERAL DAS NAÇÕES UNIDAS, 2014).

Diante dessas considerações, que compreendem que a internet instituiu um espaço ocupado por pessoas, empresas e governos, e dentro do qual os direitos fundamentais tem um papel relevante a desempenhar. Assim, passou-se a questionar o modo como o Direito deverá estar comprometido com a transição paradigmática da sociedade industrial para a sociedade da informação, especialmente como o Direito poderia sistematizar o desenvolvimento de novos campos de pesquisa e investigação que relacionassem os direitos fundamentais, a sociedade e as tecnologias da informação e comunicação.

\section{O DIREITO AO ESQUECIMENTO À LUZ DO CONCEITO DE 'DIREITOS DE PRIVACIDADE NA INTERNET'}

Ao dar início a esta seção, é relevante esclarecer que essa pesquisa filia-se à categoria de direitos construída por Bernal (2014), que consiste não apenas ao reconhecimento do direito à privacidade na internet, mas na definição de um conjunto de 'direitos de privacidade na internet'.

A discussão no entorno do tema da privacidade não é recente, como visto nos anteriormente, e a preocupação geral da sociedade com os assuntos relacionados à proteção da privacidade é significativa e crescente. Tanto é que nos recentes anúncios das empresas de tecnologia da informação e comunicação, como a Google e o Facebook, sempre são mencionadas questões vinculadas à manutenção, à melhoria ou ao comprometimento das ferramentas por eles desenvolvidas relativas à privacidade do usuário. As autoridades também têm levado a sério o tema da privacidade. Nos Estados Unidos, Google e Facebook serão auditados por 20 anos e o Twitter, por 10 anos, pela FTC - Federal Trade Comission, o órgão 
responsável pela fiscalização e proteção dos direitos do consumidor, de modo que, nesse período, as empresas venham a promover uma série de adequações relacionadas à privacidade dos usuários dos serviços por elas disponibilizado na internet (BERNAL, 2014).

Torna-se incrivelmente difícil, nos dias atuais, separar dados e informações online e off-line. Desde que a internet se tornou mais integrada com o 'mundo real', dados online e offline se misturam facilmente. Um típico exemplo de que alguns dados gerados no 'mundo real' são aproveitados dentro do ciberespaço pode ser observado no caso da rede britânica de supermercados Tesco. A partir do Tesco Clubcard, um programa de fidelidade criado pela rede, é possível coletar dados de compras realizadas no 'mundo real' que são mapeados e cruzados com compras realizadas na internet (BERNAL, 2014).

Desta forma, a rede passou a armazenar detalhes de cada consumidor no Reino Unido, desde o domicílio até uma gama de características demográficas, socioeconômicas e de estilo de vida. Por meio de um sistema de inteligência artificial, denominado Zodiac, foi possível criar perfis inteligentes e de segmentação dos dados dos clientes. Assim o perfil do cliente pode ser classificado conforme seu entusiasmo por promoções, sua fidelidade às marcas e outros hábitos de compra (LEITH, 2009).

Não bastasse isso, a companhia passou a vender o acesso à base de dados denominada Crucible a empresas de diferentes segmentos, como Sky (televisão por assinatura), Gillette (barbeadores e produtos cosméticos) e Orange (provedora de televisão e internet por assinatura). Juntos, a base de dados Crucible e o sistema Zodiac podem gerar um mapa de como um indivíduo pensa, trabalha e quais lojas frequenta. Ademais, o mapa é capaz de classificar os consumidores em 10 categorias: riqueza; promoções; viagens; caridade; consumo 'verde'; dificuldades financeiras; crédito; estilo de vida; hábitos; aventuras ("Tesco stocks up on inside knowledge of shoppers' lives", 2005).

Nesse prisma, Fortes (2015) defende a necessidade do reconhecimento de direitosbase para a efetiva proteção jurídica da privacidade e dos dados pessoais na internet, em especial na incorporação do conceito de 'direitos de privacidade na internet' como um dos pilares para a regulamentação da proteção dos dados pessoais no Brasil, buscando, assim, maior eficácia do direito fundamental à privacidade.

Nesse intuito, Bernal (2014) propõe quatro direitos-base os quais transcendem a acepção de direitos legais, já que representam desejos reais compreendidos e considerados pelas pessoas como um direito seu, sobretudo a partir da proteção da autonomia de cada indivíduo. Constituem os direitos de privacidade na internet ou, como denominados originalmente, Internet Privacy Rights: (i) o direito de navegar pela internet com privacidade; 
(ii) o direito de monitorar quem monitora; (iii) o direito de deletar os dados pessoais; (iv) o direito a uma identidade online (BERNAL, 2014).

Nesta pesquisa, contudo, serão exclusivamente elucidados elementos relacionados ao terceiro direito-base, o de deletar os dados pessoais ${ }^{2}$. Anteriormente, essa pesquisa trouxe a lume a expressão 'right to be let alone', empregada por Cooley e reproduzida por Warren e Brandeis (1890), para configurar o direito de ser deixado em paz, conferindo o início do reconhecimento do direito à privacidade (BERNAL, 2014).

Todavia, tal expressão é frequentemente entendida como sinônimo de um direito já reconhecido, inclusive no direito brasileiro, qual seja o direito ao esquecimento. Entretanto, o direito ao esquecimento, tal como se aborda nesse tópico, está adequado à conceituação utilizada por Bernal (2014), ou seja, ao denominado 'right to be forgotten', visto que vai além da simples proteção da vida privada, conferindo a possibilidade de um usuário deletar dados e informações pessoais da internet.

Um exemplo dessa confusão conceitual pode ser observado em Rulli Júnior e Rulli Neto (2012), que explicam que o direito ao esquecimento é denominado, no direito norteamericano, 'the right to be let alone'. Ele significa a garantia de que os dados sobre um indivíduo somente serão conservados para possibilitar a identificação de um sujeito conectado aos acontecimentos e apenas pelo tempo necessário ao alcance de suas finalidades. $\mathrm{O}$ direito aqui tratado, o do esquecimento, corresponde ao 'right to be forgotten', ora aprofundado.

A discussão sobre a possibilidade de ter 'um', direito ao esquecimento é antiga. Ela advém do conflito de indivíduos com a imprensa e com a mídia, em publicações não autorizadas ou cujo conteúdo não corresponderia à integralidade dos fatos e à verdade. Há alguns anos, a preocupação residia na retirada de circulação de revistas e jornais das prateleiras das bancas, para que a informação supostamente equivocada não circulasse entre os leitores, evitando-se, com isso, a deflagração de supostas inverdades. Nesse contexto, a questão vinculava-se mais ao conceito de 'right to be let alone'.

\footnotetext{
${ }^{2}$ Para saber mais sobre os quatro direitos-base, ver FORTES, Vinícius Borges. O direito fundamental à privacidade: uma proposta conceitual para a regulamentação da proteção dos dados pessoais na internet no Brasil. Tese de Doutorado, Rio de Janeiro: UNESA, 2015, 225p. Disponível em: https://www.academia.edu/17425692/O_direito_fundamental à_privacidade_uma_proposta_conceitual_para_a regulamentação_da_proteção_dos_dados_pessoais_na_internet_no_Brasil

${ }^{3}$ Nessa seção, e dentro do contexto brasileiro, este estudo não adota a denominação 'do' direito ao esquecimento, pois na percepção dos pesquisadores, trata-se de 'um' direito ao esquecimento, visto que ainda representa uma proposta interpretativa sobre o direito à privacidade e ao princípio da dignidade da pessoa humana, a partir da ponderação e de enunciados, sem a existência de norma prévia que autorize sua aplicação no contexto em análise.
} 
A questão da aplicação de 'um' direito ao esquecimento foi submetida à análise do Tribunal de Justiça da União Europeia, demandado pelo judiciário espanhol. A partir de uma ação judicial movida pelo advogado espanhol Mario Costeja contra a Google, com o objetivo de deletar um artigo do jornal La Vanguardia, datado de 1998, o qual fazia referência a um leilão de imóveis e a uma penhora por dívidas com a previdência social. Nessa circunstância, o advogado-geral da União Europeia manifestou-se, em parecer, pela não aplicação do direito ao esquecimento em casos dessa natureza.

Assim, de acordo com o advogado-geral da União Europeia, os motores de busca, no caso o Google, não devem ser responsabilizados pelo tratamento das páginas indexadas, logo não podem ser responsabilizados pelas buscas e, portanto, não podem ser obrigados a excluir determinados resultados de busca. Além disso, a determinação do Poder Judiciário direcionada ao motor de busca para o bloqueio de sites significaria a autorização judicial da censura, eis que interferiria na liberdade de expressão no ciberespaço. Ainda, a Diretiva 95/46/CE, que regulamentou o tratamento dos dados pessoais na União Europeia, possibilita a exclusão de informações inverídicas, incorretas ou incompletas. Todavia, para as informações verdadeiras, não há que se falar em 'esquecimento’ (JÄÄSKINEN, 2013).

Devido a esse tipo de demanda, a Google constituiu o que denominou "Conselho Consultivo do Google para o Direito de ser Esquecido”, formado por experts no tema. Após uma agenda de trabalho que contemplou reuniões e audiências com partes interessadas, o Conselho Consultivo emitiu, no dia 06 de fevereiro de 2015, um relatório de 44 páginas, com recomendações sobre o que a empresa de tecnologia da informação e comunicação pode fazer nos casos de requisição do direito ao esquecimento (GOOGLE, 2015).

O relatório propõe a categorização dos usuários dos serviços da Google, para fins de análise de pedidos que reivindiquem o direito ao esquecimento. De acordo com o relatório, os usuários podem ser agrupados em três diferentes categorias, conforme a sua relevância social, como mostra o quadro abaixo:

Quadro 1: Papel dos dados do sujeito na vida pública - categorias

Categorias de grupos

(a) Os indivíduos que desempenham papel na vida pública, indubitavelmente, tais como políticos, CEOs, celebridades, líderes religiosos, 'estrelas' do esportes, artistas):

(b) Indivíduos com nenhum papel perceptível na vida pública:

(c) Indivíduos com um papel limitado ou específico no contexto da vida pública, tais como diretores de escola, algumas categorias de funcionários públicos, ou indivíduos que podem desempenhar um papel público, dentro de uma comunidade, por causa de sua profissão:
Tratamento à requisição de direito ao esquecimento

pedidos de tais indivíduos são menos prováveis para justificar a exclusão de dados, uma vez que o público em geral têm interesse primordial na busca de informações sobre eles, através de uma pesquisa baseada em seus nomes. pedidos de exclusão de dados para esses indivíduos são mais propensos a justificar a exclusão.

pedidos de exclusão de dados de tais indivíduos não são nem mais nem menos prováveis para justificar, dependem especificamente do conteúdo das informações, a serem consideradas para fins de decisão de exclusão.

Fonte: Adaptado de Google (2015). 
Nesse ponto, é relevante refletir sobre os limites que uma organização empresarial como a Google, que é detentora de uma parte significativa das informações organizadas dentro da internet, de definir categorias de grupos para os quais deve ser aplicável, e sob quais circunstâncias e condições, o direito de deletar dados pessoais deverá ocorrer. A simples possibilidade de determinar ditas categorias já aponta uma fragilidade sobre as normas jurídicas que tutelam, implicitamente, o direito ao esquecimento.

Diante da liberdade de criação de limites e critérios próprios, sem qualquer intervenção do Direito sobre estes, os experts da Google categorizaram, conforme a natureza das informações, os tipos de informações que tornam o interesse em proteção da privacidade maior ou menor, como se observa nos quadros abaixo:

Quadro 2: Tipos de informações sob o viés do forte interesse de um indivíduo sobre a privacidade

Tipo de informação

Informações relacionadas à vida íntima ou ao sexo de um indivíduo

\begin{tabular}{|c|c|}
\hline $\begin{array}{l}\text { Informações } \\
\text { pessoais }\end{array}$ & $\begin{array}{l}\text { Detalhes especificos, tais como informações de conta bancária, são suscetiveis de } \\
\text { privacidade e, na maioria dos casos, garantem a exclusão das informações. } \\
\text { Informações gerais sobre a riqueza e a renda podem ser de interesse público. Por exemplo, } \\
\text { em alguns países, os salários e as propriedades dos funcionários públicos são tratados como } \\
\text { informação pública; a participação acionária em empresas públicas pode ser de interesse } \\
\text { público; pode haver preocupaços jornalísticas sobre a renda, incluindo investigações sobre } \\
\text { corrupção. }\end{array}$ \\
\hline $\begin{array}{l}\text { informações de contato ou } \\
\text { identificação privadas }\end{array}$ & $\begin{array}{l}\text { Informações como números de telefone, endereços privados, informações de contato } \\
\text { similares, números de identificação do governo, PINs, senhas, números de cartões de } \\
\text { crédito aumentam o interesse sobre os direitos de privacidade, no critério de equilibrio em } \\
\text { face do interesse público. }\end{array}$ \\
\hline $\begin{array}{l}\text { Informações considerados } \\
\text { sensíveis pela Lei } \\
\text { Proteção de } \\
\text { União Europeia }\end{array}$ & $\begin{array}{l}\text { Informações que revelem a origem racial ou étnica, opiniões politicas, crenças religiosas ou } \\
\text { filosóficas, filiação sindical, dados sobre a saúde ou a vida sexual são suscetíveis, na } \\
\text { Europa, de proteção de privacidade especifica. } \\
\text { No entanto, quando esses dados se referem a uma pessoa que desempenha papel na vida } \\
\text { pública, pode haver forte interesse público no acesso a links para obter informações através } \\
\text { de uma pesquisa baseada no nome. }\end{array}$ \\
\hline $\begin{array}{l}\text { Informações privadas sobre } \\
\text { menores }\end{array}$ & $\begin{array}{l}\text { Há uma consideração especial à privacidade de crianças e adolescentes, de acordo com a } \\
\text { Convenção das Nações Unidas sobre os Direitos da Criança. }\end{array}$ \\
\hline $\begin{array}{l}\text { Informações falsas, com } \\
\text { associações imprecisas ou } \\
\text { que coloquem pessoas em } \\
\text { risco ou causem danos }\end{array}$ & $\begin{array}{l}\text { Informações falsas ou informações que coloquem a pessoa em causa em risco de danos, tais } \\
\text { como roubo de identidade ou perseguição, pesa fortemente a favor da exclusão dos dados. }\end{array}$ \\
\hline $\begin{array}{l}\text { Informações em forma de } \\
\text { imagem ou vídeo }\end{array}$ & sas informações \\
\hline
\end{tabular}

Fonte: Adaptado de Google (2015).

Em geral, estas informações aumentam o interesse sobre os direitos de privacidade e o critério de equilibrio, em face do interesse público. As exceções são geralmente para os indivíduos que desempenham um papel na vida pública, existindo interesse público no acesso a esta informação privacidade e, na maioria dos casos, garantem a exclusão das informações. em alguns paises, os salários e as propriedades dos funcionários públicos são tratados como informação pública; a participação acionária em empresas públicas pode ser de interesse público; pode haver preocupações jornalísticas sobre a renda, incluindo investigações sobre similares, números de identificação do governo, PINs, senhas, números de cartões de crédito aumentam o interesse sobre os direitos de privacidade, no critério de equilibrio em face do interesse público.

Informações que revelem a origem racial ou étnica, opiniões politicas, crenças religiosas ou sensiveis pela Lei de Europa, de proteção de privacidade especifica.

Proteção de Dados da No entanto, quando esses dados se referem a uma pessoa que desempenha papel na vida de uma pesquisa baseada no nome

Há uma consideração especial à privacidade de crianças e adolescentes, de acordo com a

Informações falsas ou informações que coloquem a pessoa em causa em risco de danos, tais Essas informaços podem aumentar o interesse de privacidade da pessoa em causa,

Diante da categorização das informações 'tipo' e 'natureza', associada à categoria de indivíduos potencialmente interessados em sua própria privacidade, de acordo com os critérios adotados pela Google, é cabível retomar a discussão proposta no segundo capítulo da pesquisa, quando se tratou da definição de ciberespaço. Qual a dimensão pública e/ou 
privada da internet nos dias de hoje? Deveria a internet, ou parte significativa dela, ser considerada um ‘espaço público’ e, se deveria, quais seriam as implicações disso?

Se a resposta for sim, as implicações são consideráveis, não apenas para os direitos dos indivíduos e o modo como navegam pela Web ou como utilizam serviços web-based (ou seja, que dependem integralmente da internet para que sejam fornecidos e acessados), mas também para as obrigações daqueles que fornecem ou hospedam sites ou oferecem esses serviços web-based (BERNAL, 2014).

Mensurar o quão pública é a internet mostra-se absolutamente complexo. Responder esse questionamento não é algo simples, especialmente sob o ponto de vista da produção normativa clássica, e perpassa necessariamente pelo questionamento sobre o que é o ciberespaço e o que é a internet. Seriam uma simples coleção de espaços privados, conectados, cada qual com seu proprietário, suas regras e sua própria maneira de gerenciálos? (BERNAL, 2014)

A maior parte da internet é, na prática, de propriedade privada e se desenvolve como tal. Deveria a internet ser considerada algo efetivamente privado, com usuários tendo de seguir quaisquer regras definidas pelo proprietário, particularmente em termos de privacidade? Seria a internet um espaço público, administrado por regras e normas públicas, com expectativas de que os usuários deveriam ter certos direitos, e que esses direitos deveriam ser respeitados independente do modo como navegam na Web? (BERNAL, 2014)

A implicação direta da afirmação de ser a internet uma 'coisa pública', especialmente por ser considerada, nos dias atuais, uma parte intrínseca da vida contemporânea, vai ao encontro da possibilidade efetiva de os usuários reivindicarem seus direitos e vê-los respeitados, valendo isso para normas comerciais, propriedade intelectual, difamações, distribuição de conteúdo pornográfico, etc. (BERNAL, 2014). Há, no entanto, complicações, questões jurisdicionais e princípios que precisam ser desvelados. Apesar da declaração de independência do ciberespaço, proclamada por Barlow (1996), as leis têm sido aplicadas na 'vida online', com diferentes graus de êxito e de formas bastante diversas.

Pode-se considerar a internet como um significativo e extenso espaço público, sobre o qual os direitos são plenamente aplicáveis, em consequência direta, tal como a qualquer outro espaço público. Se as pessoas têm a necessidade de usar a internet e, hodiernamente, já possuem o reconhecimento do direito fundamental de acesso a ela, é evidente que deveriam existir direitos e meios de proteção adequados para sua utilização (BERNAL, 2014).

É relevante refletir sobre quais partes da internet deveriam ser consideradas públicas ou privadas e, consequentemente, de quais espécies de direito (e em especial qual o grau de 
privacidade) alguém que utilize cada uma dessas partes poderá razoavelmente gozar. A resposta mais adequada a essa reflexão, e que pode servir como um padrão, parte do pressuposto de que todos os espaços da internet deveriam ser considerados espaços públicos, exceto se houver razão convincente para o contrário (BERNAL, 2014).

$\mathrm{Na}$ sequência de categorização apresentada pelos experts da Google, foram elencados os tipos de informação, bem como a natureza desta, para efeitos de observação sob o viés do interesse público. Todavia, os tipos de informação apresentados podem colidir com o que se compreende normativamente como 'dados sensíveis', que podem revelar informações pessoais como "[...] a origem racial ou étnica, as convicções religiosas, filosóficas ou morais, as opiniões políticas, a filiação a sindicatos ou organizações de caráter religioso, filosófico ou político, dados referentes à saúde ou à vida sexual, bem como dados genéticos” (BRASIL, 2015). Nessa lógica, conforme pode-se observar no quadro abaixo, muitas das informações categorizadas dentro da natureza de interesse público, com baixa possibilidade de exclusão dos registros de internet dentro dos critérios da Google, podem violar a proteção dos dados pessoais, especificamente dos dados sensíveis.

Quadro 3: Tipos de informação no viés do interesse público

\begin{tabular}{|c|c|}
\hline lipo de informaçào & Natureza d \\
\hline $\begin{array}{l}\text { Informações relevantes para } 0 \\
\text { discurso político, } 0 \\
\text { envolvimento do cidadão ou a } \\
\text { governança }\end{array}$ & $\begin{array}{l}\text { O discurso político é fortemente relacionado ao interesse público, incluindo opiniões e } \\
\text { discussões de crenças politicas de outras pessoas. Raramente deve ser excluido. }\end{array}$ \\
\hline $\begin{array}{l}\text { Informações relevantes para } 0 \\
\text { discurso religioso ou filosófico }\end{array}$ & $\begin{array}{l}\text { Os discursos religioso e filosofico são fortemente vinculados ao interesse publico, } \\
\text { incluindo opiniões e discussões de crenças religiosas e filosóficas de outras pessoas. } \\
\text { Raramente devem ser excluidos }\end{array}$ \\
\hline $\begin{array}{l}\text { Informações que se relacionam } \\
\text { com a saúde pública e a defesa } \\
\text { do consumidor }\end{array}$ & $\begin{array}{l}\text { As informações públicas relacionadas a questões de saúde ou de defesa do consumidor } \\
\text { pesam fortemente contra a remoção. } \\
\text { Por exemplo, as avaliações de serviços profissionais oferecidos ao público em geral } \\
\text { podem impactar a segurança do consumidor. Este valor é amplamente reconhecido, } \\
\text { hoje em dia, no contexto de jornalismo. Fontes, como os usuários individuais de sites } \\
\text { de midia social fornecem, muitas vezes, esse tipo de informação, melhor do que uma } \\
\text { fonte jornalistica tradicional. }\end{array}$ \\
\hline $\begin{array}{l}\text { Informações relacionadas à } \\
\text { atividade criminal }\end{array}$ & $\begin{array}{l}\text { Os dados relativos a infracções ou condenações penais merecem tratamento especial ao } \\
\text { abrigo da Lei de Proteção de Dados da União Europeia. } \\
\text { Onde as leis especificas, relativas ao tratamento desses dados, emitirem orientações } \\
\text { claras, estas devem prevalecer. } \\
\text { Quando não se aplica nenhuma regra, o resultado será diferente, dependendo do } \\
\text { contexto. } \\
\text { As considerações separadas - gravidade do crime, papel desempenhado pelo solicitante } \\
\text { na atividade criminosa, atualização, fonte da informação (ambos discutidos adiante) - } \\
\text { bem como o grau de interesse público na informação em questão são particularmente } \\
\text { relevantes para a avaliação desses casos. } \\
\text { A avaliação do interesse público na exclusão dos dados pode ser diferente, dependendo } \\
\text { se eles dizem respeito a um infrator criminal ou à vítima de uma ofensa criminal. As } \\
\text { informações sobre as violações dos direitos humanos e os crimes contra a humanidade } \\
\text { devem pesar contra a exclusão. }\end{array}$ \\
\hline $\begin{array}{l}\text { Informação que contribui para } \\
\text { um debate sobre uma questão } \\
\text { de interesse geral }\end{array}$ & $\begin{array}{l}\text { O público tem interesse em acessar opiniões individuais e na discussão de informações } \\
\text { que contribuam para o debate público sobre uma questão de interesse geral (por } \\
\text { exemplo, disputas industriais ou prática fraudulenta). } \\
\text { A determinação de uma contribuição para o debate público pode ser informada pelo } \\
\text { critério de origem, discutido a seguir. No entanto, uma vez que informações sobre um } \\
\text { assunto ou evento em particular sejam consideradas a contribuir para um debate }\end{array}$ \\
\hline
\end{tabular}




\begin{tabular}{|c|c|}
\hline & $\begin{array}{l}\text { público, haverá preconcepção contra a exclusão de alguma informação sobre esse } \\
\text { assunto, independente de origem. }\end{array}$ \\
\hline $\begin{array}{c}\text { Informações factuais e } \\
\text { verdadeiras }\end{array}$ & $\begin{array}{l}\text { Informações factuais e verdadeiras que não colocam ninguém em risco de danos pesam } \\
\text { contra a exclusão das informações. }\end{array}$ \\
\hline $\begin{array}{c}\text { Informações para o registro } \\
\text { histórico }\end{array}$ & $\begin{array}{l}\text { Quando o conteúdo refere-se a uma figura ou a eventos históricos, há forte interesse } \\
\text { público em acessá-lo facilmente online, através de uma pesquisa baseada em nome. } \\
\text { Isso pesa contra a exclusão de informações. } \\
\text { Os casos mais fortes incluem links para informações a respeito de crimes contra a } \\
\text { humanidade. }\end{array}$ \\
\hline $\begin{array}{l}\text { Informações relacionadas à } \\
\text { investigação científica ou de } \\
\text { expressão artística }\end{array}$ & $\begin{array}{l}\text { Em alguns casos, a remoção de links de resultados de busca baseados em nome } \\
\text { distorcerá a investigação científica. } \\
\text { Nestes casos, leva-se em consideração o valor para o interesse público. } \\
\text { A importância artística de um conteúdo constitui interesse público e vai pesar contra a } \\
\text { exclusão. Por exemplo, se a pessoa em causa é retratada em uma paródia artística, isto } \\
\text { vai pesar a favor de um interesse público na informação. }\end{array}$ \\
\hline
\end{tabular}

Fonte: Adaptado de Google (2015).

Apesar de não ter apresentado aspectos mais conclusivos relacionados ao futuro do reconhecimento jurídico do direito ao esquecimento, o relatório do conselho consultivo do Google para o direito de ser esquecido trouxe contribuições interessantes para o debate e análise desse direito, a partir de diferentes visões que observaram um modelo de negócio indubitavelmente baseado na Web simbiótica.

Considerando isso, é relevante observar que a categorização de possibilidades de aplicação efetiva do direito ao esquecimento não deveria ocorrer como um direito absoluto, mas com sua aplicação em equilíbrio com outros direitos. Assim, o direito ao esquecimento poderia ser sempre aplicado, exceto em determinadas circunstâncias categóricas, definidas expressamente na norma jurídica, e não em critérios singulares definidos pela pelo próprio agente responsável pelo armazenamento e tratamento dos dados.

Assim, desde que consideradas juridicamente, as limitações poderiam estar fundamentadas em razões paternalistas, para o bem do indivíduo; por razões comunitárias, para o bem da comunidade; por razões administrativas e econômicas, inclusive registros eleitorais e fiscais; por razões de arquivamento, inclusive de registros jornalísticos e históricos; por razões de liberdade de expressão; por razões de segurança nacional ou de prevenção de crimes (BERNAL, 2014).

Superada a questão envolvendo o caráter público ou privado gerado pela internet no ciberespaço, é imprescindível analisar outra questão relevante, diretamente vinculada ao tema tratado nesse capítulo: o que confere aos dados pessoais a natureza privada de 'nossos' e de 'pessoais'? Nesse mister, é fundamental estabelecer uma diferença relevante para essa pesquisa: em países de matriz jurídica anglo-saxônica, como os Estados Unidos, algumas formas de dados são consideradas suficientemente pessoais, a ponto de o indivíduo deter alguns direitos sobre todos esses dados; nos países de matriz jurídica romano-germânica, 
como a maior parte dos países europeus, considera-se qualquer dado que possa estar diretamente ligado a um indivíduo como um dado pessoal (BERNAL, 2014).

Destarte, uma possível resposta seria uma mudança de paradigma que vá ao encontro dos questionamentos já evidenciados, em especial à natureza mista de uma internet que ora se mostra um espaço público, ora se apresenta como espaço privado. Em um espaço privado os indivíduos controlariam suas próprias configurações de privacidade. Em um espaço público, eles requisitariam a proteção por meio de direitos de privacidade. Em qualquer dos casos, o paradigma a ser mudado é o de que a privacidade deixa de ser uma exceção para tornar-se regra geral (BERNAL, 2014). Essa mudança de paradigma é fundamental para que a vigilância, ou a surveillance como sugere a tese de Morais e Neto (2014), não mais tenha um pressuposto de aceitabilidade, assim como a coleta, o processamento e o armazenamento de dados pessoais, seja qual for o fim.

Havendo a mudança paradigmática, tornando-se a proteção da privacidade regra geral, aqueles que desejarem monitorar pessoas ou coletar, utilizar, armazenar dados pessoais precisariam justificar, razoavelmente, os motivos para a vigilância, a coleta, a utilização ou o armazenamento de dados e informações pessoais. Se a justificativa não for plausível, aceitável ou não estiver prevista dentro das exceções instituídas por uma norma jurídica que reconheça e positive, de maneira efetiva, o direito à privacidade e à proteção dos dados pessoais na internet, tais dados não poderão jamais ser objeto de vigilância, coleta, utilização e armazenamento. Logo, a mudança de paradigma deve adotar o modelo de proteção da privacidade como regra básica, principalmente nos espaços constituídos na e pela internet (BERNAL, 2014).

Assim, o direito de deletar informações pessoais não tem como pretensão fortalecer a censura ou reescrever a história, mas unicamente fornecer aos indivíduos mais controle sobre suas informações pessoais, assim como incentivar empresas e governos a se apropriarem, de modo mais eficiente, de dados adequados e úteis para atender determinado fim, sem trazer qualquer risco de dano ou exposição demasiada de dados e informações pessoais (BERNAL, 2014).

Dos quatro direitos-base que compõem o núcleo do conceito de 'direitos de privacidade na internet', o direito a deletar dados pessoais na internet, de modo específico, já foi demandado no âmbito judicial no Brasil. Em março de 2013, o Conselho da Justiça Federal do Brasil (CJF) instituiu o Enunciado 531, durante a VI Jornada de Direito Civil do Centro de Estudos do Judiciário do Conselho da Justiça Federal, prescrevendo a recomendação interpretativa de que "A tutela da dignidade da pessoa humana na sociedade da 
informação inclui o direito ao esquecimento" (CONSELHO DA JUSTIÇA FEDERAL, 2013).

De acordo com o referido enunciado, a interpretação do artigo 11 do Código Civil Brasileiro ${ }^{4}$ deve considerar que

\begin{abstract}
Os danos provocados pelas novas tecnologias de informação vêm-se acumulando nos dias atuais. $\mathrm{O}$ direito ao esquecimento tem sua origem histórica no campo das condenações criminais. Surge como parcela importante do direito do ex-detento à ressocialização. Não atribui a ninguém o direito de apagar fatos ou reescrever a própria história, mas apenas assegura a possibilidade de discutir o uso que é dado aos fatos pretéritos, mais especificamente o modo e a finalidade com que são lembrados (CONSELHO DA JUSTIÇA FEDERAL, 2013).
\end{abstract}

Evidentemente, no contexto brasileiro, 'o' direito ao esquecimento cumpre, há tempos, o objetivo de ressocialização daquele que infringe a lei, particularmente em matéria penal $^{5}$. Observa-se, entretanto, no Enunciado 531 do CJF, a proposta de interpretação do Código Civil Brasileiro, de modo a aplicar 'um' direito ao esquecimento a casos distintos e sem a necessária relação com questões envolvendo reabilitação criminal.

Ainda que a preocupação exposta pelo Conselho da Justiça Federal seja sociologicamente legítima, a discussão estabelecida em escala global vai no sentido de refletir se o judiciário tem legitimidade para determinar, de acordo com sua 'consciência', a instituição de um 'botão delete', conforme o caso. Como se evidencia, nos casos a seguir expostos, a aplicação de 'um' direito ao esquecimento é realizada com base na interpretação por enunciados e pela ponderação (ou sopesamento) de princípios constitucionais, o que merece atenção e análise científica aprofundadas, especialmente à luz da crítica formulada por Streck (2012b).

Diante da aplicação recente da ponderação de princípios constitucionais em casos envolvendo a garantia de 'um' direito ao esquecimento, evidencia-se, na jurisprudência brasileira do Superior Tribunal de Justiça (STJ), maior elucidação da (in)adequação da técnica bem como da (in)adequação do processo interpretativo, a partir de enunciados e súmulas,

\footnotetext{
${ }^{4}$ Art. 11 - Com exceção dos casos previstos em lei, os direitos da personalidade são intransmissíveis e irrenunciáveis, não podendo o seu exercício sofrer limitação voluntária.

${ }^{5}$ Conforme o artigo 748 do Código de Processo Penal, “A condenação ou condenações anteriores não serão mencionadas na folha de antecedentes do reabilitado, nem em certidão extraída dos livros do juízo, salvo quando requisitadas por juiz criminal". Nesse contexto, o reabilitado tem o direito ao esquecimento exclusivamente junto aos registros oficiais em relação a seus antecedentes.
} 
como vem ocorrendo nas circunstâncias de fortalecimento do dito direito ao esquecimento no ciberespaço ${ }^{6}$.

Indiscutivelmente, as questões relacionadas à internet são dotadas de complexidade, as quais, em diversas oportunidades, convertem-se em perplexidade. Apresenta-se, a título exemplificativo, o caso envolvendo Maria da Graça Xuxa Meneghel versus Google Internet Brasil Ltda., em que a autora da ação pretendia a eliminação integral de todos os resultados de busca envolvendo a pesquisa com os termos "xuxa pedófila" ou quaisquer outros que tivessem relação com seu nome. Ao final, o site de buscas foi vitorioso, não havendo o reconhecimento, nesse caso, do direito ao esquecimento, por conta da impossibilidade técnica de o motor de buscas realizar a eliminação do conteúdo pretendido pela autora da ação (observe-se que a decisão do Superior Tribunal de Justiça firmou-se em questão de tecnologia da informação e não em fundamentos jurídicos propriamente ditos).

Causa perplexidade diante do complexo tema enfrentado no Recurso Especial n. ${ }^{\circ}$ 1.316.921 - RJ (2011/0307909-6), relatado pela ministra Nancy Andrighi, a justificativa de voto do ministro Massami Uyeda. Conforme o trecho, a seguir, transcrito, o julgador reconhece o voto da relatora como o "melhor caminho, no momento", ainda que desconheça, tanto no campo jurídico, quanto na órbita tecnológica, o tema julgado:

Da forma como está, efetivamente, a solução preconizada pela Sra. Ministra Nancy Andrighi é, como S. Exa. mesmo ressaltou, o melhor caminho, no momento. Mas, efetivamente, é preciso que haja, também, um mecanismo de defesa, porque, embora o direito à informação seja essencial para esse mundo em que vivemos, a realidade é que a honra e intimidade, devem ser preservadas.

Então, talvez, exatamente não possa atribuir isso, atribuiria isso ao meu próprio não conhecimento da área, de desconhecer a possibilidade de buscar uma origem. [...].

Quero agradecer esse esclarecimento técnico, confesso o meu não conhecimento, mas espero um dia chegar a compreender esse mecanismo e acompanho integralmente o voto da eminente Relatora, dando provimento ao recurso especial. (grifo nosso). (BRASIL, 2013).

Se há uma certeza no voto transcrito é a de que, em circunstâncias determinadas, a postura do Poder Judiciário brasileiro é distante da teoria do Direito. Por tal razão, é fundamental o aprofundamento dos temas relacionados à análise da aplicação da ponderação em conflitos de princípios constitucionais, em que se concentra a raiz do ativismo judicial brasileiro.

\footnotetext{
${ }^{6}$ Ressalta-se que esta pesquisa se limita a analisar esse caso, no que diz respeito à jurisprudência brasileira, eis que as análises jurisprudenciais não fazem parte do escopo desta investigação. Apresenta-se esse caso concreto apenas a título exemplificativo de recente julgamento no Brasil, diretamente relacionado com o direito-base de deletar os dados pessoais na internet.
} 
Para Streck (2012, p. 12), a utilização da ponderação possibilitou a construção do pan-principiologismo, "uma bolha especulativa dos princípios". Para ele, a ausência de critérios no uso da ponderação possibilitou o "[...] aumento da fragmentação da aplicação do Direito, sendo um dos motivos do surgimento das súmulas vinculantes e da repercussão geral no Brasil [...]". Por essas razões, não causa qualquer surpresa a utilização, em julgados do STJ, do Enunciado 531 do CJF, ficando evidente o uso, além da ponderação, da interpretação por enunciados como subsídio para concluir pelo reconhecimento de 'um' direito ao esquecimento, conforme se observa no trecho, na sequência, transcrito:

\begin{abstract}
A tese do direito ao esquecimento ganha força na doutrina jurídica brasileira e estrangeira, tendo sido aprovado, recentemente, o Enunciado n. ${ }^{\circ} 531$ na VI Jornada de Direito Civil promovida pelo CJF/STJ [...].

Cabe desde logo separar o joio do trigo e assentar uma advertência. A ideia de direito ao esquecimento ganha ainda mais visibilidade - mas também se torna mais complexa - quando aplicada à internet, ambiente que por excelência, não esquece o que nele é divulgado e pereniza tanto informações honoráveis quanto aviltantes à pessoa do noticiado, sendo desnecessário lembrar o alcance potencializado de divulgação próprio desse cyberespaço. Até agora, tem-se mostrado inerente a ela - a existência de um 'resíduo informacional' que supera a contemporaneidade da notícia e, por vezes, pode ser, no mínimo, desconfortante àquele que é noticiado. (grifos do autor) (BRASIL, 2012).
\end{abstract}

Observa-se, de modo inequívoco, o uso da ponderação 'à brasileira', ou seja, um sopesamento distorcido e a aplicação da interpretação por enunciados, criticada por Streck (2011). Pela análise desenvolvida, não há dúvidas de que o uso da ponderação e da interpretação por enunciados, da maneira como estabelecida nos acórdãos revisados, não se mostra adequado à resolução do conflito jurídico sobre o direito ao esquecimento, estabelecido e recepcionado para julgamento pelo Superior Tribunal de Justiça.

Aliás, a postura adotada pelo Poder Judiciário brasileiro, especialmente no caso apresentado, é um dos elementos onde se pode identificar a necessidade de incorporação do conceito de 'direitos de privacidade na internet', sobretudo pelos direitos-base a ele vinculados. Ademais, ainda que os fatores técnicos sejam relevantes, não é admissível que a proteção de direitos fundamentais esteja diretamente (e quase que exclusivamente, como no caso Xuxa vs. Google) vinculada à impossibilidade de cumprimento de decisão judicial por fatores técnicos. Ainda assim, a justificativa técnica aceita pelo STJ não parece ser absoluta, tendo em vista o cumprimento da decisão judicial da corte espanhola, que determinou a exclusão das informações pessoais pelo Google. Portanto, sob o prisma da tecnologia da informação, é viável o cumprimento de decisões que aplicam o direito-base de deletar os dados pessoais na internet, ainda que disposto implicitamente, como é o caso do sistema de diretivas e regulamentos de proteção de dados pessoais na União Europeia. 


\section{CONCLUSÃO}

$\mathrm{Na}$ busca de resposta ao problema formulado, a pesquisa cumpriu com o objetivo geral e com os três objetivos específicos, delineados em cada um dos capítulos desta pesquisa.

O direito-base de deletar os dados pessoais, o qual se filia ao direito ao esquecimento na acepção do right to be forgotten, mantem relação direta com os impactos sobre a proteção jurídica do direito à privacidade e à proteção dos dados pessoais. Contudo, a norma jurídica brasileira vigente não possibilita eventuais exclusões de dados por razões de foro íntimo e que não sejam consequência de ato ilícito de terceiro, limitando-se à possibilidade de cancelamento de cadastro em bancos de dados, dando margem para interpretações equivocadas pelo Poder Judiciário ou a adoção temerária de diretrizes por empresas privadas do setor de tecnologia da informação.

A imprecisão conceitual dentro das normas jurídicas, no que tange ao contexto da internet, especialmente na tutela da privacidade e da inviolabilidade dos dados pessoais, é elemento relevante para sustentar que os direitos de privacidade na internet necessitam estar incorporados conceitualmente (FORTES, 2015) para assegurar plena eficácia ao direito fundamental à privacidade, sobretudo por recepcionar em seu bojo a proteção da vida privada, da intimidade, da imagem, da honra e dos direitos-base, especialmente o de deletar dados pessoais.

Conceber a privacidade na internet como um direito fundamental, em sentido amplo, capaz de recepcionar em seu bojo a proteção da vida privada, da intimidade, da imagem, da honra e dos direitos-base vinculados ao conceito de direitos de privacidade na internet, significa dizer que, na contemporaneidade, o direito de deletar dados pessoais deve ser tutelado como um dos pilares de garantia da eficácia do direito fundamental à privacidade em sentido amplo.

\section{REFERÊNCIAS}

ASSEMBLEIA GERAL DAS NAÇÕES UNIDAS. The Universal Declaration of Human Rights. Disponível em: <http://www.un.org/en/documents/udhr/index.shtml>. Acesso em: 14 mar. 2015.

ASSEMBLEIA GERAL DAS NAÇÕES UNIDAS. Resolution adopted by the General 
Assembly on 18 December 2014 - 69/166. The right to privacy in the digital age. [s.l: s.n.].

BARLOW, J. P. A Declaration of the Independence of Cyberspace. Disponível em: <https://projects.eff.org/ barlow/Declaration-Final.html>. Acesso em: 23 fev. 2011.

BERNAL, P. Internet privacy rights: rights to protect autonomy. Cambridge (UK): Cambridge University Press, 2014.

BRASIL. Decreto n. ${ }^{\circ}$ 592/1966. Disponível em: <http://www.planalto.gov.br/ccivil_03/decreto/1990-1994/D0592.htm>. Acesso em: 14 jan. 2015.

BRASIL. Superior Tribunal de Justiça. Acórdão em Recurso Especial n. ${ }^{0} 1.334 .097$ - RJ (2012/0144910-7). Relator Ministro Luís Felipe Salomão.

BRASIL. Superior Tribunal de Justiça. Acórdão em Recurso Especial n. ${ }^{0} 1.316 .921$ - RJ (2011/0307909-6). Relatora Ministra Nancy Andrighi. Disponível em: $<$ https://ww2.stj.jus.br/processo/revista/documento/mediado/?componente=ITA\&sequencial= $1161904 \&$ num_registro=201103079096\&data=20120629\&formato=PDF $>$.

BRASIL. Anteprojeto de Lei para a Proteção de Dados Pessoais. Disponível em: $<$ http://participacao.mj.gov.br/dadospessoais/texto-em-debate/anteprojeto-de-lei-para-aprotecao-de-dados-pessoais/>. Acesso em: 28 abr. 2015.

CONSELHO DA JUSTIÇA FEDERAL. Enunciado trata do direito ao esquecimento na sociedade da informação. Disponível em: <http://www.cjf.jus.br/cjf/noticias-docjf/2013/abril/enunciado-trata-do-direito-ao-esquecimento-na-sociedade-da-informacao>. Acesso em: 14 jan. 2014.

DONEDA, D. Da privacidade à proteção de dados pessoais. Rio de Janeiro: Renovar, 2006.

FORTES, V. B. O direito fundamental à privacidade: uma proposta conceitual para a regulamentação da proteção dos dados pessoais na internet no brasil. 2015. Universidade Estácio de Sá, 2015. Disponível em:

<https://www.academia.edu/17425692/O_direito_fundamental_à_privacidade_uma_proposta _conceitual_para_a_regulamentação_da_proteção_dos_dados_pessoais_na_internet_no_Brasi $1>$.

GOOGLE. Report of The Advisory Council to Google on the Right to be Forgotten Members of the Council. [s.l: s.n.]. Disponível em: $<$ https://drive.google.com/file/d/0B1UgZshetMd4cEI3SjlvV0hNbDA/view>.

GREENWALD, G.; KAZ, R.; CASADO, J. EUA espionaram milhões de e-mails e ligações de brasileiros - Jornal O Globo. O Globo, jul. 2013. Disponível em:

$<$ http://oglobo.globo.com/mundo/eua-espionaram-milhoes-de-mails-ligacoes-de-brasileiros8940934\#ixzz2q7eRkKbW>. Acesso em: 3 jan. 2015.

JÄÄSKINEN, N. Conclusões do advogado-geral apresentadas em 25 de junho de 2013 Processo C-131/12 - Google Spain SL, Google Inc. vs. Agencia Española de Protección de Datos, Mario Costeja González. [s.l: s.n.]. 
JÚNIOR, A. R.; NETO, A. R. Direito ao Esquecimento e o Superinformacionismo Apontamentos no Direito Brasileiro dentro do Contexto de Sociedade da Informação. Revista do Instituto do Direito Brasileiro, v. 1, n. 2012, p. 419-434, 2012. Disponível em: <http://www.idb-fdul.com/uploaded/files/RIDB_001_0419_0434.pdf>.

LEITH, P. Privacy as slogan. In: SAARENPÄ̈̈, A. (Ed.). Legal privacy. Zaragoza: Prensas de la Universidad de Zaragoza, 2009. p. 93-112.

MORAIS, J. L. B.; NETO, E. J. A insuficiência do Marco Civil da Internet na proteção das comunicações privadas armazenadas e do fluxo de dados a partir do paradigma da surveillance. In: LEITE, G.; LEMOS, R. (Ed.). Marco Civil da Internet. São Paulo: Atlas, 2014. p. 417-439.

RODOTÀ, S. A vida na sociedade da vigilância: a privacidade hoje. Rio de Janeiro: Renovar, 2008.

SALDAÑA, M. N. “The right to privacy”. La génesis de la protección de la privacidad en el sistema constitucional norteamericano: el centenario legado de Warren y Brandeis. Revista de Derecho Político, n. 85, p. 195-240, 2012.

STRECK, L. Hermenêutica jurídica e(m) crise: uma exploração hermenêutica da construção do direito. 10. ed. Porto Alegre: Livraria do Advogado, 2011.

STRECK, L. Segunda parte - as réplicas: neoconstitucionalismo, positivism e póspositivismo. In: STRECK, L.; TRINDADE, A. K.; FERRAJOLI, L. (Ed.). Garantismo, hermenêutica e (neo)constitucionalismo: um debate com Luigi Ferrajoli. Porto Alegre: Livraria do Advogado, 2012a. p. 260.

STRECK, L. L. O que é isto - decido conforme a minha consciência? Porto Alegre: Livraria do Advogado, 2012b.

TAPPER, C. Computers and the law. [s.l.] Weidenfeld \& Nicolson, 1973.

Tesco stocks up on inside knowledge of shoppers' lives. The Guardian, 20 set. 2005. Disponível em:

<http://www.theguardian.com/business/2005/sep/20/freedomofinformation.supermarkets>. Acesso em: 8 fev. 2015.

WARNER, M.; STONE, M. G. The data bank society: organizations, computers and social freedom. [s.1.] Allen \& Unwin, 1970.

WARREN, S. D.; BRANDEIS, L. D. The Right to Privacy. Harvard Law Review VO - 4, n. 5, p. 193, 1890. Disponível em:

<http://roble.unizar.es:9090/login?url=http://search.ebscohost.com/login.aspx?direct=true\&db $=$ edsjsr\&AN=edsjsr.10.2307.1321160\&lang=es\&site=eds-live $>$. 